\title{
Detection of Polyps After Resection of Colorectal Cancer
}

\author{
Jin-Hee Paik, Eun-Joo Jung, Chun-Geun Ryu, Dae-Yong Hwang \\ Department of Surgery, Colorectal Cancer Center, Konkuk University Medical Center, Konkuk University School of Medicine, Seoul, Korea
}

Purpose: Because colonoscopy after colorectal cancer surgery is important for detecting synchronous or metachronous colorectal neoplasms, we designed this study to investigate, by using postoperative colonoscopy, the miss rate for and the location of polyps remaining after colorectal cancer surgery.

Methods: In a prospectively-collected patient database, 264 patients were shown to have undergone a colorectal cancer resection between May 2012 and June 2013. Of these, 116 who had received a complete colonoscopy preoperatively and postoperatively were included in this study.

Results: Of these 116 patients, 68 were males and 48 were females; their mean age was 63 years. The mean time after surgery at which postoperative colonoscopy was performed was 7.1 months (range, 3-15 months). On postoperative colonoscopy, a total of 125 polyps were detected. Of these, there were no cancerous lesions; 46 (36.8\%) were neoplastic polyps, and $79(63.2 \%)$ were nonneoplastic polyps. Fifty-nine polyps (47.2\%) and 15 polyps (12\%) were located in the proximal and the distal parts of the anastomosis, respectively. The miss rates for the total numbers of polyps and of neoplastic polyps remaining after surgery were $37.4 \%$ and $24.2 \%$, respectively. The incidence of neoplastic polyps increased during postoperative colonoscopy as it had during preoperative colonoscopy $(\mathrm{r}=0.164, \mathrm{P}=0.048)$.

Conclusion: Colonoscopic surveillance after colorectal cancer resection results in the detection of pathologic polyps in one-fourth of the cases. During postoperative colonoscopy, careful examination of the proximal colon is necessary. $\mathrm{Pa}$ tients in whom multiple neoplastic polyps had been detected during preoperative colonoscopy require careful and thorough follow-up.

\section{Keywords: Colonic polyps; Colorectal neoplasms; Colonoscopy}

\section{INTRODUCTION}

In colorectal cancer patients, preoperative and postoperative colonoscopies are essential for detecting synchronous and metachronous colorectal neoplasms. In general, the incidence of metachronous colorectal cancer is reported to be between $1.1 \%$ and $3.6 \%$ [1-3], and in patients with colorectal cancer, the incidence of neoplastic polyps found during postoperative colonoscopic surveillance is reported to be about $17 \%$ to $30 \%[4,5]$. The National

Received: September 9, 2015 - Accepted: September 25, 2015

Correspondence to: Dae-Yong Hwang, M.D.

Department of Surgery, Colorectal Cancer Center, Konkuk University Medical

Center, Konkuk University School of Medicine, 158 Gwanjeodong-ro,

Seo-gu, Daejeon 35365, Korea

Tel: +82-2-2030-5111, Fax: +82-2-2030-5112

E-mail: hwangcrc@kuh.ac.kr

(C) 2015 The Korean Society of Coloproctology

This is an open-access article distributed under the terms of the Creative Commons Attribution NonCommercial License (http://creativecommons.org/licenses/by-nc/3.0) which permits unrestricted non-

commercial use, distribution, and reproduction in any medium, provided the original work is properly cited.
Comprehensive Cancer Network (NCCN) guidelines recommend postoperative colonoscopic surveillance to detect colorectal polyps during the first year following surgery [6].

Because most polyps detected during preoperative colonoscopy are removed before radical surgery, whether those detected during postoperative colonoscopy within one year of the surgery are polyps that were missed during the preoperative colonoscopy or metachronous lesions is not know. Furthermore, the incidence of remaining polyps is not well known, and the locations, distributions, and clinicopathologic features of these remaining lesions are not clear. For these reasons, in this research, we estimated the incidence and the distribution of the polyps, both neoplastic and nonneoplastic, remaining after a curative colorectal resection in patients with colorectal.

\section{METHODS}

All data were extracted from a prospectively collected colorectal cancer patients' database. Of the 264 patients who underwent a 
curative resection for colorectal cancer between May 2012 and June 2013, 116 who had undergone complete preoperative and postoperative colonoscopies were enrolled in this study. Patients were excluded based on the following criteria: patients in whom the colonoscope could not pass through the colorectal lesion due to a luminal obstruction, patients who had undergone preoperative concurrent chemoradiation therapy, patients who had undergone palliative surgery, and the patients who had undergone postoperative colonoscopy at other clinics. In the 116 enrolled patients, all polyps detected during preoperative colonoscopy had been removed. The colon was defined as being from the cecum to the rectosigmoid junction. The right colon was defined as being from the cecum to the transverse colon, and the left colon was defined as being from the splenic flexure to the rectosigmoid junction.

The miss rate of polyps was calculated as follows [4]: total number of missed polyps/(total number of missed polyps + total number of polyps detected on the initial colonoscopy).

Data analysis was performed using the SPSS ver. 17.0 (SPSS Inc., Chicago, IL, USA). Summary statistics using the Student t-test with Welch correction, the Mann-Whitney test, and the chisquare test were used to compare the number of polyps according to their locations and sizes. Statistical significance was set at a Pvalue less than 0.05 .

\section{RESULTS}

Among the 116 patients, 68 were males and 48 were females; their mean age was 63 years (range, 20-85 years). Postoperative colonoscopy was performed 7.1 months (mean) after radical surgery (range, 3-15 months). The location of the primary colorectal can-

Table 1. Characteristics of patients $(n=116)$

\begin{tabular}{lc}
\hline Characteristic & Value \\
\hline Sex & $68: 48$ \\
$\quad$ Male:female & $63.0 \pm 1.1(20-85)$ \\
Age (yr) & $7.1 \pm 0.2(3-15)$ \\
Interval between operation and postoperative & \\
$\quad$ colonoscopy (mo) & \\
Location of the primary tumor & \\
Institute at which preoperative colonoscopy exam & \\
was performed & $63(54.3)$ \\
Our institute & $53(45.7)$ \\
Other institute & \\
TNM Stage & $44(37.9)$ \\
I & $42(36.2)$ \\
॥ & $21(18.1)$ \\
III & $9(7.8)$ \\
\hline IV
\end{tabular}

Values are presented as mean \pm standard deviation (range) or number (\%). cer was within the colon in 102 patients and within the rectum in 14 patients. Preoperative colonoscopy was performed in $63 \mathrm{pa}-$ tients at this institute and in 53 patients at other clinics. The TNM stage was stage I in 44 patients, stage II in 42 patients, stage III in 21 patients, and stage IV in 9 patients. The patients' characteristics are shown in Table 1. Polyps were classified according to their size $(\mathrm{cm}):<0.5 ; \geq 0.5,<1.0$; and $\geq 1.0$.

During preoperative colonoscopy, a total of 209 polyps were detected: for 87 polyps, size $(\mathrm{cm})<0.5$; for 84 polyps, $0.5 \leq$ size $(\mathrm{cm})$ $<1.0$; and for 38 polyps, size $(\mathrm{cm}) \geq 1.0$. Of the 87 polyps for which size $(\mathrm{cm})<0.5,41$ were located in the right colon, 35 were located in the left colon, and 11 were located in the rectum. Of the 84 polyps for which $0.5 \leq$ size $(\mathrm{cm})<1.0,40$ were located in the right colon, 38 were located in the left colon, and 6 were located in the rectum. Of the 38 polyps for which size $(\mathrm{cm}) \geq 1.0,12$ were located in the right colon, 22 were located in the left colon, and 4 were located in the rectum (Table 2). Table 3 shows the relationship between the polyps and the primary tumor during preoperative colonoscopy. One hundred 45 polyps $(69.4 \%)$ from the primary tumor were located in the proximal colon $(\mathrm{P}<0.001)$. The sizes of 38 of 209 polyps (18.2\%) were $\geq 1.0 \mathrm{~cm}(\mathrm{P}=0.002)$.

The histologic types of the polyps found during preoperative colonoscopy are presented in Table 4: 4 synchronous colorectal cancers (1.9\%), 140 neoplastic polyps (67\%), and 65 nonneoplastic polyps (31.1\%). Among the 140 neoplastic polyps, the most common histologic types were tubular adenomas (130 polyps, $62.2 \%$ ), villotubular adenomas (9 polyps, $4.3 \%$ ), and a villous adenoma ( 1 polyp, $0.5 \%$ ). Among the 65 nonneoplastic polyps, the

Table 2. Polyp distribution during preoperative colonoscopy according to location and size

\begin{tabular}{lcccr}
\hline \multirow{2}{*}{ Location } & \multicolumn{3}{c}{ Size $(\mathrm{cm})$} & \multirow{2}{*}{ Total } \\
\cline { 2 - 4 } & $<0.5$ & $\leq 0.5,<1$ & $\geq 1$ & \\
\hline Right colon & $41(19.6)$ & $40(19.1)$ & $12(5.7)$ & $93(44.5)$ \\
Left colon & $35(16.7)$ & $38(18.2)$ & $22(10.5)$ & $95(45.5)$ \\
Rectum & $11(5.3)$ & $6(2.9)$ & $4(1.9)$ & $21(10.0)$ \\
Total $(\%)$ & $87(41.6)$ & $84(40.2)$ & $38(18.2)$ & $209(100)$ \\
\hline
\end{tabular}

Values are presented as number (\%).

Right colon, from the cecum to the distal transverse colon; left colon, from the splenic flexure to the rectosigmoid junction.

Table 3. Polyp location based on the size of primary tumor during preoperative colonoscopy

\begin{tabular}{lcccc}
\hline \multirow{2}{*}{ Location } & \multicolumn{3}{c}{ Size $(\mathrm{cm})$} & \multirow{2}{*}{ Total } \\
\cline { 2 - 4 } & $<0.5$ & $\leq 0.5,<1$ & \multicolumn{1}{c}{$\geq 1$} & \\
\hline Proximal & $55(26.3)$ & $62(29.7)$ & $28(13.4)$ & $145(69.4)$ \\
Distal & $32(15.3)$ & $22(10.5)$ & $10(4.8)$ & $64(30.6)$ \\
Total & $87(41.6)$ & $84(40.2)$ & $38(18.2)$ & $209(100)$ \\
\hline
\end{tabular}

Values are presented as number (\%). 
Table 4. Histologic types of the polyps detected during preoperative colonoscopy

\begin{tabular}{lcccc}
\hline Histologic types of the & \multicolumn{5}{c}{ Size (cm) } & \multirow{2}{*}{ Total } \\
\cline { 2 - 4 } polyps & $<0.5$ & $\leq 0.5,<1$ & $\geq 1$ & \\
\hline $\begin{array}{l}\text { Synchronous neoplasm } \\
\text { Neoplastic polyp }\end{array}$ & $0(0)$ & $1(0.5)$ & $3(1.4)$ & $4(1.9)$ \\
$\quad$ Tubular adenoma & $42(20.1)$ & $64(30.6)$ & $24(11.5)$ & $130(62.2)$ \\
$\quad$ Villotubular adenoma & $0(0)$ & $2(0.9)$ & $7(3.3)$ & $9(4.3)$ \\
$\quad$ Villous adenoma & $0(0)$ & $0(0)$ & $1(0.5)$ & $1(0.5)$ \\
Nonneoplastic polyp & & & & \\
$\quad$ Hyperplastic polyp & $19(4.3)$ & $11(5.3)$ & $2(0.9)$ & $32(15.3)$ \\
$\quad$ Inflammatory polyp & $26(12.4)$ & $6(2.9)$ & $1(0.5)$ & $33(15.8)$ \\
Total & $87(41.6)$ & $84(40.2)$ & $38(18.2)$ & $209(100)$ \\
\hline
\end{tabular}

Values are presented as a number (\%).

Table 5. Polyp distribution during postoperative colonoscopy according to its location and size

\begin{tabular}{lcccc}
\hline \multirow{2}{*}{ Location } & \multicolumn{3}{c}{ Size $(\mathrm{cm})$} & \multirow{2}{*}{ Total } \\
\cline { 2 - 4 } & $<0.5$ & $\leq 0.5,<1$ & $\geq 1$ & \\
\hline Right colon & $38(30.4)$ & $13(10.4)$ & $1(0.8)$ & $52(41.6)$ \\
Left colon & $50(40.0)$ & $6(4.8)$ & $4(3.2)$ & $60(48.0)$ \\
Rectum & $11(8.8)$ & $6(4.8)$ & $4(3.2)$ & $21(16.5)$ \\
Total (\%) & $99(79.2)$ & $20(16.0)$ & $6(4.8)$ & $125(100)$ \\
\hline
\end{tabular}

Values are presented as number (\%).

Right colon, from the cecum to the distal transverse colon; left colon, from the splenic flexure to the rectosigmoid junction.

incidences of hyperplastic polyps and inflammatory polyps were similar (15.3\% and $15.8 \%$, respectively).

During postoperative colonoscopy, a total of 125 polyps were detected. The anatomical distributions of the polyps were similar between the preoperative and the postoperative colonoscopies. However, most of the polyps found during the postoperative colonoscopies had sizes $<0.5 \mathrm{~cm}$ (99 polyps, 79.2\%) (Table 5). According to the location based on anastomosis, 59 polyps (47.2\%) were located in the proximal part of the anastomosis, 15 (12\%) were located in the distal part of the anastomosis, and 51 (40.8\%) were located at the anastomotic site, as shown in Table $6(\mathrm{P}<$ 0.001 ). The histologic results for the polyps detected by postoperative colonoscopy are shown in Table 7. Among the 125 polyps, no cancerous polyps were detected; $46(36.8 \%)$ were neoplastic polyps and $79(63.2 \%)$ were nonneoplastic polyps. All neoplastic polyps (46 polyps) were tubular adenomas (Table 7). In the subgroup analysis of the neoplastic polyps detected by postoperative colonoscopy, neoplastic polyps were commonly located in the right colon and the proximal part of the anastomosis $(60.9 \%$ and $82.6 \%$, respectively, both $\mathrm{P}<0.001$ ) (Table 8 ).

In the 116 enrolled patients, the incidence of total polyps during
Table 6. Polyp location based on the anastomosis during postoperative colonoscopy

\begin{tabular}{lcccc}
\hline \multirow{2}{*}{ Location } & \multicolumn{3}{c}{ Size $(\mathrm{cm})$} & \multirow{2}{*}{ Total } \\
\cline { 2 - 4 } & $<0.5$ & $\leq 0.5,<1$ & $\geq 1$ & \\
\hline Proximal & $40(32.0)$ & $14(11.2)$ & $5(4.0)$ & $59(47.2)$ \\
Distal & $11(8.8)$ & $3(2.4)$ & $1(0.8)$ & $15(12.0)$ \\
Anastomosis & $48(38.4)$ & $3(2.4)$ & $0(0)$ & $51(40.8)$ \\
Total & $99(79.2)$ & $20(16.0)$ & $6(4.8)$ & $125(100)$ \\
\hline
\end{tabular}

Values are presented as number (\%).

Table 7. Histologic types of the polyps detected during postoperative colonoscopy

\begin{tabular}{lcccc}
\hline \multirow{2}{*}{$\begin{array}{l}\text { Histologic types of the } \\
\text { polyps }\end{array}$} & \multicolumn{3}{c}{ Size (cm) } & \multirow{2}{*}{ Total } \\
\cline { 2 - 4 } & $<0.5$ & $\leq 0.5,<1$ & $\geq 1$ & \\
\hline Cancer & $0(0)$ & $0(0)$ & $0(0)$ & $0(0)$ \\
Neoplastic polyp & & & & \\
$\quad$ Tubular adenoma & $27(21.6)$ & $13(10.4)$ & $6(4.8)$ & $46(36.8)$ \\
$\quad$ Villotubular adenoma & $0(0)$ & $0(0)$ & $0(0)$ & $0(0)$ \\
$\quad$ Villous adenoma & $0(0)$ & $0(0)$ & $0(0)$ & $0(0)$ \\
Nonneoplastic polyp & & & & \\
$\quad$ Hyperplastic polyp & $9(7.2)$ & $4(3.2)$ & $0(0)$ & $13(10.4)$ \\
$\quad$ Inflammatory polyp & $63(50.4)$ & $3(2.4)$ & $0(0)$ & $66(52.8)$ \\
Total & $99(79.2)$ & $20(16.0)$ & $6(4.8)$ & $125(100)$ \\
\hline
\end{tabular}

Values are presented as number (\%).

Table 8. Locations of the neoplastic polyps detected during postoperative colonoscopy

\begin{tabular}{lcc}
\hline Location & No. (\%) & P-value \\
\hline Right colon & $28(60.9)$ & $<0.001$ \\
Left colon & $16(34.8)$ & \\
Rectum & $2(4.3)$ & \\
From primary tumor & & $<0.001$ \\
Proximal & $38(82.6)$ & \\
Distal & $8(17.4)$ & \\
\hline
\end{tabular}

Right colon, from the cecum to the distal transverse colon; left colon, from the splenic flexure to the rectosigmoid junction.

postoperative colonoscopy was $53.4 \%$ (62 out of 116 patients), and the incidence of neoplastic polyps was $25.9 \%$ (30 out of 116 patients). According to the previous definition of the miss rate, the miss rate for the total number of polyps was $37.4 \%$, and the miss rate for neoplastic polyps was $24.2 \%$. A Spearman correlation analysis showed that the incidence of neoplastic polyps increased during postoperative colonoscopy just as the incidence of neoplastic polyps had increased during preoperative colonoscopy $(\mathrm{r}=0.164, \mathrm{P}=0.048)$. On the other hand, no correlation was 
found between the detection of nonneoplastic polyps and that of neoplastic polyps $(\mathrm{P}=0.252$, postoperative; $\mathrm{P}=0.410)$.

\section{DISCUSSION}

In this study, the miss rate for neoplastic polyps found during postoperative, but not preoperative, colonoscopy was $24.2 \%$. Higher percentages of the missed neoplastic polyps were located in the right colon and the proximal part from the primary tumor percentage. The more neoplastic polyp detected during preoperative colonoscopy was associated with the more missed neoplastic polyp detected during postoperative colonoscopy.

In colorectal cancer patients, postoperative colonoscopic surveillance is the most useful strategy for early detection of polyps and metachronous colorectal cancer [7]. The NCCN guidelines recommend postoperative colonoscopy surveillance within the first year after a colorectal cancer resection [8]. If a patient is unable to undergo a complete colonoscopy preoperatively due to an obstructive lesion, colonoscopy should be performed within 3-6 months of the surgery. However, whether or not a patient who did not have a preoperative obstruction needs to undergo postoperative colonoscopy within the first year is a subject of debate [9-11].

In most studies, postoperative colonoscopy was performed within the first year [4, 12]. Bensen et al. [4] showed that the miss rate for all polyps, including neoplastic and nonneoplastic polyps, was $17 \%$ and that the miss rate for neoplastic polyps was $12 \%$. Pickhardt et al. [13] estimated that the miss rate for neoplastic polyps was $12 \%$. Patel and Ahnen reported that the miss rate for neoplastic polyps ranged from $17 \%-47 \%[14,15]$. Rex et al. [16] demonstrated that the pooled miss rates for nonneoplastic polyps and neoplastic polyps were $27 \%$ and $22 \%$, respectively. In this aspect, the suggestion that colonoscopic surveillance should be performed within the first year seems persuasive. On the other hand, Cone et al. [17] proposed that extending the time to the first colonoscopy appears to be safe because the incidence of polyps with sizes $\geq 1 \mathrm{~cm}$ was $3.2 \%$. At this institute, colonoscopic surveillance is performed 6-8 months after surgery. Despite the interval being shorter than those reported in other papers, the incidence of missed polyps was high, the miss rate for total polyps being $37.4 \%$ and the miss rate for neoplastic polyps being 24.2\%. Especially, in our study, the sizes of most neoplastic polyps were $<5 \mathrm{~mm}$, and the incidence of polyps with sizes $\geq 1 \mathrm{~cm}$ was $4.8 \%$. Therefore, whether one year is the proper time interval for postoperative colonoscopic surveillance is questionable.

Our study showed that the missed neoplastic polyps were commonly located in the right colon and the proximal part from the primary tumor. The reason for these results is not clear. However, recent studies proposed a hypothesis that the mechanisms of polyp formation differ depending on the location of the polyp. Several studies have suggested that proximal colon cancers were more often associated with microsatellite instability (MSI) - high, $B R A F$ mutation. Also, they showed that distal colon cancers were related to chromosomal instability, epidermal growth factor receptor or human epidermal growth factor receptor 2 amplification, and overexpression of epiregulin [17-21]. Considering that a neoplastic polyp might be a premalignant lesion for colorectal cancer, these different mechanisms for colorectal cancer between the right and the left colon might have led to the difference in the distributions of neoplastic polyps.

Kawai et al. [22] showed that the presence of synchronous polyps influenced the adenoma-free survival in patients who underwent a curative resection. Similarly, our study showed that a higher number of neoplastic polyps detected during preoperative colonoscopy was associated with a higher number of missed neoplastic polyps being detected during postoperative colonoscopy.

In addition, some studies have demonstrated a correlation between the detection of neoplastic polyps and the detection of nonneoplastic polyps in patients who undergo screening colonoscopy within the first year following surgery $[22,23]$. However, no correlation between the detection of non-neoplastic polyps and that of neoplastic polyps was observed in the present study.

Although many studies have evaluated polyps in colorectal cancer patients, very few references have reported evaluations of the histologic results for the anastomotic site. Our study showed that the histologic types of the polyps at the anastomosis were nonneoplastic polyps, especially inflammatory polyps. These data were similar to those reported by Weinstock and Shatz [24] and suggest that the most commonly observed abnormality at the anastomosis is inflammatory polyps.

The probable reasons polyps were missed on the preoperative colonoscopy were incomplete bowel preparation, inappropriate withdrawal technique, inadequate polypectomy, and lower skill level of the endoscopist. Consequently, we should carefully evaluate the patient's history, such as family history, previous numbers of polyps, and histologic dysplasia in previous polyps. In addition, we should educate surgeons about good bowel preparation, determine the colonoscopic withdrawal time, and cooperate with the pathologist for achieving complete pathologic assessment.

In conclusion, polyps are located in the right colon during postoperative colonoscopy, especially in the proximal part from the primary tumor. Therefore, the endoscopist should carefully evaluate the right colon and the proximal part of the anastomosis during postoperative colonoscopic surveillance. In particular, patients in whom multiple neoplastic polyps were detected during preoperative colonoscopy should be closely and carefully followed.

\section{CONFLICT OF INTEREST}

No potential conflict of interest relevant to this article was reported.

\section{REFERENCES}

1. Mulder SA, Kranse R, Damhuis RA, Ouwendijk RJ, Kuipers EJ, 
van Leerdam ME. The incidence and risk factors of metachronous colorectal cancer: an indication for follow-up. Dis Colon Rectum 2012;55:522-31.

2. Hollington P, Tiong L, Young G. Timing and detection of metachronous colorectal cancer. ANZ J Surg 2011;81:272-4.

3. Le Clercq CM, Winkens B, Bakker CM, Keulen ET, Beets GL, Masclee AA, et al. Metachronous colorectal cancers result from missed lesions and non-compliance with surveillance. Gastrointest Endosc 2015;82:325-33.e2.

4. Bensen S, Mott LA, Dain B, Rothstein R, Baron J. The colonoscopic miss rate and true one-year recurrence of colorectal neoplastic polyps. Polyp Prevention Study Group Am J Gastroenterol 1999;94:194-9.

5. Lee KH, Kim HC, Yu CS, Myung SJ, Yang SG, Kim JC. Colonoscopic surveillance after curative resection for colorectal cancer with synchronous adenoma. Korean J Gastroenterol 2005;46:381-7.

6. Choe EK, Park KJ, Chung SJ, Moon SH, Ryoo SB, Oh HK. Colonoscopic surveillance after colorectal cancer resection: who needs more intensive follow-up? Digestion 2015;91:142-9.

7. Levin B, Lieberman DA, McFarland B, Andrews KS, Brooks D, Bond J, et al. Screening and surveillance for the early detection of colorectal cancer and adenomatous polyps, 2008: a joint guideline from the American Cancer Society, the US Multi-Society Task Force on Colorectal Cancer, and the American College of Radiology. Gastroenterology 2008;134:1570-95.

8. National Comprehensive Cancer Network. Patient and Caregiver Resources [Internet]. Fort Wathington: National Comprehensive Cancer Network; c2014 [cited 2015 Jun 10]. Available from: http://www.nccn.org/patients.

9. Renehan AG, Egger M, Saunders MP, O’Dwyer ST. Impact on survival of intensive follow up after curative resection for colorectal cancer: systematic review and meta-analysis of randomised trials. BMJ 2002;324:813.

10. Niv Y, Half B, Moshkowitz M, Kariv R, Vilkin A, Levi Z. Surveillance of patients after colonoscopic polypectomy and curative resection of colorectal cancer. Harefuah 2010;149:670-3, 682.

11. Figueredo A, Rumble RB, Maroun J, Earle CC, Cummings B, McLeod R, et al. Follow-up of patients with curatively resected colorectal cancer: a practice guideline. BMC Cancer 2003;3:26.

12. Anthony T, Simmang C, Hyman N, Buie D, Kim D, Cataldo P, et al. Practice parameters for the surveillance and follow-up of patients with colon and rectal cancer. Dis Colon Rectum 2004;47: 807-17.

13. Pickhardt PJ, Nugent PA, Mysliwiec PA, Choi JR, Schindler WR.
Location of adenomas missed by optical colonoscopy. Ann Intern Med 2004;141:352-9.

14. Patel SG, Ahnen DJ. Prevention of interval colorectal cancers: what every clinician needs to know. Clin Gastroenterol Hepatol 2014;12:7-15.

15. van Rijn JC, Reitsma JB, Stoker J, Bossuyt PM, van Deventer SJ, Dekker E. Polyp miss rate determined by tandem colonoscopy: a systematic review. Am J Gastroenterol 2006;101:343-50.

16. Rex DK, Kahi CJ, Levin B, Smith RA, Bond JH, Brooks D, et al. Guidelines for colonoscopy surveillance after cancer resection: a consensus update by the American Cancer Society and US MultiSociety Task Force on Colorectal Cancer. CA Cancer J Clin 2006; 56:160-7.

17. Cone MM, Beck DE, Hicks TE, Rea JD, Whitlow CB, Vargas HD, et al. Timing of colonoscopy after resection for colorectal cancer: are we looking too soon? Dis Colon Rectum 2013;56:1233-6.

18. Yamauchi M, Morikawa T, Kuchiba A, Imamura Y, Qian ZR, Nishihara R, et al. Assessment of colorectal cancer molecular features along bowel subsites challenges the conception of distinct dichotomy of proximal versus distal colorectum. Gut 2012;61: 847-54.

19. Minoo P, Zlobec I, Peterson M, Terracciano L, Lugli A. Characterization of rectal, proximal and distal colon cancers based on clinicopathological, molecular and protein profiles. Int J Oncol 2010;37:707-18.

20. Missiaglia E, Jacobs B, D’Ario G, Di Narzo AF, Soneson C, Budinska E, et al. Distal and proximal colon cancers differ in terms of molecular, pathological, and clinical features. Ann Oncol 2014;25: 1995-2001.

21. Maus MK, Hanna DL, Stephens CL, Astrow SH, Yang D, Grimminger PP, et al. Distinct gene expression profiles of proximal and distal colorectal cancer: implications for cytotoxic and targeted therapy. Pharmacogenomics J 2015;15:354-62.

22. Kawai K, Ishihara S, Yamaguchi H, Sunami E, Kitayama J, Miyata $\mathrm{H}$, et al. Nomogram prediction of metachronous colorectal neoplasms in patients with colorectal cancer. Ann Surg 2015;261:92632.

23. Atia MA, Patel NC, Ratuapli SK, Boroff ES, Crowell MD, Gurudu $\mathrm{SR}$, et al. Nonneoplastic polypectomy during screening colonoscopy: the impact on polyp detection rate, adenoma detection rate, and overall cost. Gastrointest Endosc 2015;82:370-5.e1.

24. Weinstock LB, Shatz BA. Endoscopic abnormalities of the anastomosis following resection of colonic neoplasm. Gastrointest Endosc 1994;40:558-61. 